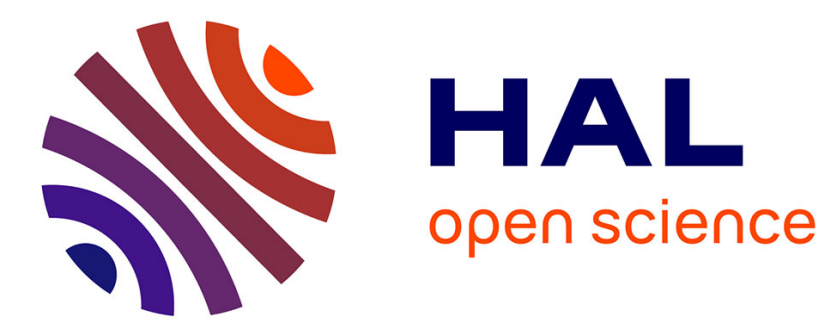

\title{
Characterisation of HIV-1 from patients with virological failure to a Boosted protease inhibitor regimen
}

\author{
Marie Rathcke Lillemark, Jan Gerstoft, Niels Obel, Gitte Kronborg, Court
}

Pedersen, Louise Bruun Jørgensen, Tina Vasehus Madsen, Terese Lea

Katzenstein

\section{To cite this version:}

Marie Rathcke Lillemark, Jan Gerstoft, Niels Obel, Gitte Kronborg, Court Pedersen, et al.. Characterisation of HIV-1 from patients with virological failure to a Boosted protease inhibitor regimen. Journal of Medical Virology, 2011, 83 (3), pp.377. 10.1002/jmv.21997 . hal-00610728

\section{HAL Id: hal-00610728 \\ https://hal.science/hal-00610728}

Submitted on 24 Jul 2011

HAL is a multi-disciplinary open access archive for the deposit and dissemination of scientific research documents, whether they are published or not. The documents may come from teaching and research institutions in France or abroad, or from public or private research centers.
L'archive ouverte pluridisciplinaire HAL, est destinée au dépôt et à la diffusion de documents scientifiques de niveau recherche, publiés ou non, émanant des établissements d'enseignement et de recherche français ou étrangers, des laboratoires publics ou privés. 


\section{Characterisation of HIV-1 from patients with virological failure to a Boosted protease inhibitor regimen}

\begin{tabular}{|c|c|}
\hline Journal: & Journal of Medical Virology \\
\hline Manuscript ID: & JMV-10-1959.R1 \\
\hline Wiley - Manuscript type: & Research Article \\
\hline $\begin{array}{r}\text { Date Submitted by the } \\
\text { Author: }\end{array}$ & 29-Sep-2010 \\
\hline Complete List of Authors: & $\begin{array}{l}\text { Lillemark, Marie; State Serum Institute, Department of Virology } \\
\text { Gerstoft, Jan; University Hospital of Copenhagen, Department of } \\
\text { Infectious Diseases } \\
\text { Obel, Niels; University Hospital of Copenhagen, Department of } \\
\text { Infectious Diseases } \\
\text { Kronborg, Gitte; University Hospital of Copenhagen, Hvidovre } \\
\text { Hospital, Department of Infectious Diseases } \\
\text { Pedersen, Court; Odense University Hospital, Department of } \\
\text { Infectious Diseases } \\
\text { Jørgensen, Louise; State Serum Institute, Department of Virology } \\
\text { Madsen, Tina; State Serum Institute, Department of Virology } \\
\text { Katzenstein, Terese; University Hospital of Copenhagen, } \\
\text { Department of Infectious Diseases }\end{array}$ \\
\hline Keywords: & Ritonavir, Resistance, PI plasma concentrations, Gag CS \\
\hline
\end{tabular}


TABLE I.

Sex, origin, mode of transmission and treatment initiation information on the 1007 patients receiving PI/r during the study period, and the 23 patients failing this treatment.

Sex, origin, mode of transmission and treatment initiation information on the 1007 patients receiving $\mathrm{PI} / \mathrm{r}$ during the study period, and the 23 patients failing this treatment. $210 \times 297 \mathrm{~mm}(600 \times 600 \mathrm{DPI})$ 
Subtype, viral load, plasma drug concentrations and mutations in the pol and gag genes from baseline and failure samples from the 19 patients from Copenhagen chosen for molecular analysis. Aminoacids are numbered according to the HXB2 reference sequence for the pol and gag genes seperately.

$297 \times 210 \mathrm{~mm}(600 \times 600 \mathrm{DPI})$ 


\section{TITLE PAGE}

2 Characterisation of HIV-1 from patients with virological failure to a Boosted protease

3 inhibitor regimen

4 M.Sc. Marie Rathcke Lillemark'; Prof. MD, DMSc. Jan Gerstoft ${ }^{2}$; MD, DMSc. Niels

5 Obel ${ }^{2,3} ;$ MD. DMSc. Gitte Kronborg ${ }^{4}$; Prof. MD, DMSc. Court Pedersen ${ }^{5}$; M.Sc. PhD

6 Louise Bruun Jørgensen ${ }^{1}$; M.Sc. PhD Tina Vasehus Madsen¹; MD, DMSc. Terese Lea

$7 \quad$ Katzenstein $^{2}$

8

$9{ }^{1}$ Department of Virology, Statens Serum Institut, Copenhagen, Denmark

$10{ }^{2}$ Department of Infectious Diseases, University Hospital of Copenhagen, Copenhagen,

11 Denmark

$12{ }^{3}$ The Danish HIV Cohort Study, University Hospital of Copenhagen, Copenhagen,

13 Denmark

$14{ }^{4}$ Department of Infectious Diseases, University Hospital of Copenhagen, Hvidovre

15 Hospital, Hvidovre, Denmark

$16{ }^{5}$ Department of Infectious Diseases, Odense University Hospital, Odense, Denmark

18 Short title: HIV-1 patients failing boosted PI

19 Corresponding author: Marie Rathcke Lillemark

Statens Serum Institut

Artillerivej 5

Department of Virology

Virus Biosafety (BL-3) Laboratory

DK - 2300 Copenhagen S

Phone: +453268 3407

Fax: +4532683082 


\section{ABSTRACT}

2 The use of highly active antiretroviral treatment (HAART) regimens with unboosted pro-

3 tease inhibitors (PIs) has resulted in a high level of virological failure primarily due to

4 the development of resistant virus. Current boosted PI regimens combine successfully

5 low-dose ritonavir ( $r$ ) with a second PI. The aim was to estimate the proportion of pa-

6 tients, in a population based setting, who develop virological failure on a $\mathrm{Pl} / \mathrm{r}$ regimen.

7 Through The Danish HIV Cohort Study 1007 patients who received $\mathrm{Pl} / \mathrm{r}$ based treat-

8 ment between 1995 and 2008 were identified. Twenty-three (2.3\%) experienced vi-

9 rological failure, of whom 19 (83\%) started $\mathrm{Pl} / \mathrm{r}$ treatment before 2001 . Patients from

10 Copenhagen $(n=19)$ were selected to study the development of protease (PR) and gag

11 cleavage site (CS) mutations during $\mathrm{PI} / \mathrm{r}$ treatment and $\mathrm{PI}$ plasma levels at the time of

12 virological failure. Three patients (16\%) developed major PI resistance mutations.

13 Mutations in the p7/p1 and p1/p6 gag CS only developed in patients with major or

14 minor mutations in PR. Drug concentrations were low or undetectable in 10 out of the

1519 patients. In total PR resistance mutations and low drug levels could account for 12

$16(63 \%)$ of the failure cases. In conclusion, virological failure to $\mathrm{Pl} / \mathrm{r}$ is a low and

17 decreasing problem primarily caused by low plasma drug levels and to a lesser extent

18 major PR mutations. Gag CS mutations did not contribute significantly to resistance

19 development and virological failure.

20

21 KEY WORDS

22 Ritonavir, resistance, PI plasma concentrations, gag CS 


\section{1}

\section{INTRODUCTION}

2 During maturation of the Human immunodeficiency virus type 1 (HIV-1) viral particle

3 the PR enzyme cleaves the gag polyprotein into functional proteins essential to the in-

4 fectious virus [Loeb et al., 1989; Katz and Skalka 1994; Mammano et al., 1998]. The

5 gag polyprotein contains five specific protease cleavage sites (CS), p24/p17, p17/p2,

$6 \mathrm{p} 2 / \mathrm{p} 7, \mathrm{p} 7 / \mathrm{p} 1$ and $\mathrm{p} 1 / \mathrm{p} 6$ with different affinity for the enzyme. These are cleaved at spe-

7 cific rates and order to obtain the mature infectious viral particle. Protease inhibitors

8 (PI) block the cleavage activity of PR by binding to the active site of the enzyme and

9 thereby hinder the maturation of the virus [Ashorn et al., 1990; McQuade et al., 1990]. HAART regimens with unboosted PIs have shown a high level of virological failure primarily due to the development of resistant virus. Resistance towards Pls arises when specific major resistance mutations appear in the PR gene, causing a conformational change in the enzyme's active site. This lowers the affinity to the PIs and allows for cleavage to occur. Minor mutations develop secondarily to restore loss of viral fitness and replication capacity implied by the major mutations [Gulnik et al., 1995; Croteau et al., 1997; Borman et al., 1996; Nijhuis et al., 1999; Mammano et al., 2000]. Current boosted PI regimens combine low-dose ritonavir with a second high-dose PI $(\mathrm{Pl} / \mathrm{r})$. This decreases the degradation rate by the cytochrome $\mathrm{P} 450$ enzyme in the liver and increases blood and intracellular levels of the PIs [Moyle and Back, 2001] which

20 has proven to decrease the risk of virological failure and resistance development [Coo21 per et al., 2003; Lima et al., 2008].

A previous study [Ananworanich et al., 2006] found a low prevalence (3.8\%) of virological failure in patients on $\mathrm{Pl} / \mathrm{r}$ regimens. Von Wyl et al., [2007], found that only $30 \%$ of

$24 \mathrm{Pl} / \mathrm{r}$ failure patients harboured resistance mutations and Ananworanich et al., 2006, 25 found no resistance mutations in nine patients with $\mathrm{Pl} / \mathrm{r}$ failure. The major reasons for 26 failure on $\mathrm{Pl} / \mathrm{r}$ regimens in the absence of resistance have not been determined, though

27 theories such as altered absorption and metabolism of the PIs in patients failing $\mathrm{PI} / \mathrm{r}$ 
1 have been suggested as an explanation for the low plasma concentrations and subse-

2 quent virological failure seen in some patients [Zazzi, 2007].

3 Since gag is the natural substrate for PR, mutations in or around the gag cleavage

4 sites have been linked to PI resistance development. Some studies assign a compen-

5 satory fitness role to gag CS mutations [Zhang et al., 1997; Doyon et al., 1996; Bally et

6 al., 2000], whereas others found resistance development based exclusively on muta-

7 tions in gag [Verheyen et al., 2006; Nijhuis et al., 2007; Prabu-Jeyabalan et al., 2004].

8 Some studies have looked in gag outside the CS and found non-CS mutations leading

9 to improved viral replication [Gatanaga et al., 2002; Myint et al., 2004; Aoki et al.,

10 2009]. Ghosn et al., 2009, suggested that the emergence of certain gag CS mutations

11 could predict virological failure. Though the exact role of gag CS and non-CS mutations

12 is yet to be determined, it is widely accepted that specific mutations such as A431V

13 and $1437 \mathrm{~V}$ in $\mathrm{p} 7 / \mathrm{p} 1$ and $\mathrm{R} 452 \mathrm{~S}$ in $\mathrm{p} 1 / \mathrm{p} 6$ can contribute to continued viral replication in

14 the presence of PIs [Zhang et al., 1997; Verheyen et al., 2006; Nijhuis et al., 2007; My-

15 int et al., 2004; Malet et al., 2007].

16 The purpose of the present study was to estimate the proportion of patients, in a popu-

17 lation based setting, who develop virological failure on a $\mathrm{Pl} / \mathrm{r}$ based regimen. A group of

18 patients was selected for molecular analysis to study the development of PR and gag

19 mutations during $\mathrm{Pl} / \mathrm{r}$ treatment as well as the plasma concentration levels of the PIs at

20 the time of virological failure. 


\section{PATIENTS AND METHODS}

\section{Setting}

3 The estimated HIV-1 prevalence among adults in Denmark is $0.07 \%$ [Lohse et al.,

42005 ]. About $60 \%$ of the patients are infected with subtype B virus [Jørgensen et al;

5 2003]. Medical care, including antiretroviral treatment (ARV), is tax-paid and provided

6 free-of-charge to all residents of Denmark infected with HIV-1. During the study's fol-

7 low-up period, national criteria for initiating HAART were HIV-1-related disease, acute

8 HIV-1 infection, pregnancy, CD4 cell count $<300$ cells/ $\mu$, and, until 2001, plasma HIV-

$9 \quad 1-\mathrm{RNA}>100,000$ copies $/ \mathrm{ml}$.

11 Study population

12 Patients were identified through The Danish HIV Cohort Study, described earlier

13 [Lohse et al., 2005]. In brief, this cohort encompasses all patients infected with HIV-1

14 seen at Danish HIV treatment clinics since $1^{\text {st }}$ of January 1995 . The Danish HIV Cohort

15 Study is approved by the Danish Data Protection Agency (J-no: 2001-41-0624).

16 All patients who, as of December $31^{\text {st }} 2008$, had received treatment with a $\mathrm{Pl} / \mathrm{r}$ regimen

17 including Saquinavir, Indinavir, Atazanavir or Lopinavir and with no prior failure to unboosted PI were identified from the cohort. Patients with previous virological failure to a

19 non-PI containing regimen were included in the study population.

20 The patients with virological failure while compliant with a boosted PI regimen were 21 identified from the study population. Virological failure was defined as plasma HIV-122 RNA >400 copies/ml in two consecutive measurements minimum four weeks apart af23 ter at least three months of compliance to a continuous $\mathrm{Pl} / \mathrm{r}$ regimen or after HIV-124 RNA had been $<20$ copies/ml. Patient files of the failure patients were scrutinised to evaluate compliance. For almost all patients with virological failure or rebound the rea-

26 sons for this had been discussed with the patient. Patients who had stopped treatment

27 or who reported regularly missing treatment doses were excluded. Information on the 
1 degree of compliance (i.e. percentage of missed doses) had not been collected sys-

2 tematically.

3 For the molecular analysis of the pol and gag genes, all failure patients seen at the two

4 HIV treating centres in Copenhagen, managing 2/3 of the Danish HIV patients, were

5 selected. Plasma samples obtained at or after the time of failure, and baseline samples

6 obtained prior to any PI treatment were analysed. Failure samples taken more than two

7 months after the failure criteria had been fulfilled were only included if the patient re-

8 ceived the same $\mathrm{Pl} / \mathrm{r}$ treatment at failure and sample date.

9 The study was approved by The Danish National Committee on Biomedical

10 Research Ethics (H-D-2009-017). Informed consent was obtained from each patient.

$12 \quad$ PCR and sequencing

13 Sequences of the pol region were extracted from the Danish HIV Sequence Database

14 housed at the Department of Virology, State Serum Institute, which includes sequences

15 from resistance tests performed on samples from Danish HIV patients from 2000 to

16 2008. The database currently includes approximately 5000 sequences from 1200 pa-

17 tients. The Danish HIV Sequence Database is approved by the Danish Data Protection

18 Agency (J-no: 2006-41-6709).

19 If the sequence was not available from the database, RNA from stored plasma samples

20 was extracted using QiaAmp viral RNA mini kit (Qiagen, Hilden, Germany). The pol

21 gene including the PR and reverse transcriptase (RT) regions was amplified and se-

22 quenced using a previously described in house nested RT-PCR method amplifying

231302 bp [Madsen et al., 2007].

24 Amplification of the complete gag gene was done using primers JA152 [Leitner et al.,

25 1995] and XM1_mod (modified from Gatanaga et al., 2002) for both cDNA (65 ํ, 10

$\left.26 \min ; 42{ }^{\circ} \mathrm{C}, 5 \mathrm{~min} ; 42^{\circ} \mathrm{C}, 1 \mathrm{~h}, 99 \stackrel{\circ}{\circ} \mathrm{C}, 3 \mathrm{~min}\right)$ and first round of PCR (94 ${ }^{\circ} \mathrm{C}, 10 \mathrm{~min}$; (94

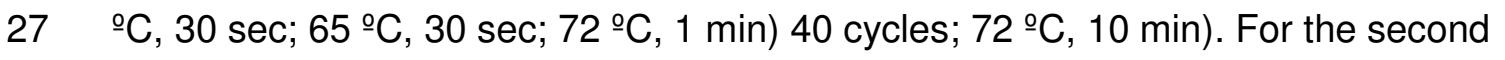


1 round of $\mathrm{PCR}\left(94^{\circ} \mathrm{C}, 30 \mathrm{sec} ; 65^{\circ} \mathrm{C}, 30 \mathrm{sec} ; 72^{\circ} \mathrm{C}, 1 \mathrm{~min}\right) 30$ cycles; $\left.72{ }^{\circ} \mathrm{C}, 10 \mathrm{~min}\right)$

2 primers LF3 [Gatanaga et al., 2002] and TVM1_R 5'-

3 CСTCCAАTTCCСССТАТСАТTTTTG-3' (in-house) were used, generating a 1723 bp

$4 \quad$ PCR-fragment including all five PR cleavage sites.

5 The gag sequences were obtained using BigDye ${ }^{\circledR}$ Terminator v1.1 Cycle Sequencing

6 Kit (Applied Biosystems, CA, USA) with primers LF3, TVM1_R, TVM_seq1 5'-

7 AAGACACCAAGGAAGC-3', TVM_seq2 5'-TTCCTAGGGGCCCTGCAATT-3',

8 TVM_seq3 5'-ACTTTTACCCATGCATT-3' and TVM_seq4 5'-

9 ACATTAGAAGAAATGATG-3' (all in-house).

10 The population based sequences were run on an ABI PRISM® 3100 Genetic Analyzer

11 (Applied Biosystems, CA, USA).

13 Sequence analysis

14 Sequences (Genbank accession numbers: AM933271-AM933291; AM933522-

15 AM933542) were analysed using SeqScape v2.5 (Applied Biosystems, CA, USA) and

16 Bionumerics v5.0 (Applied Maths, Sint-Martens-Latem, Belgium) and aligned using

17 Clustal W in Geneious v4.7 (Biomatters Ltd, Auckland, New Zealand). Phylogenetic

18 neighbour-joining tree analyses for subtyping and quality control were carried out using

19 Geneious v4.7 (Biomatters Ltd, Auckland, New Zealand). Sequences from the Danish HIV Sequence Database and subtype specific references from the Los Alamos Sequence Database (http://www.hiv.lanl.gov/) were included as reference sequences.

22 Resistance associated mutations in pol according to the Stanford HIV Drug Resistance

23 Database [Liu and Shafer; 2006; last updated June 10, 2008] were identified. Full gag

24 sequences from pre-treatment and failure samples were aligned pairwise in order to 25 detect mutations in the five CS regions that had developed during treatment. CS re26 gions were defined by five amino acids (aa) on each side of the CS. 


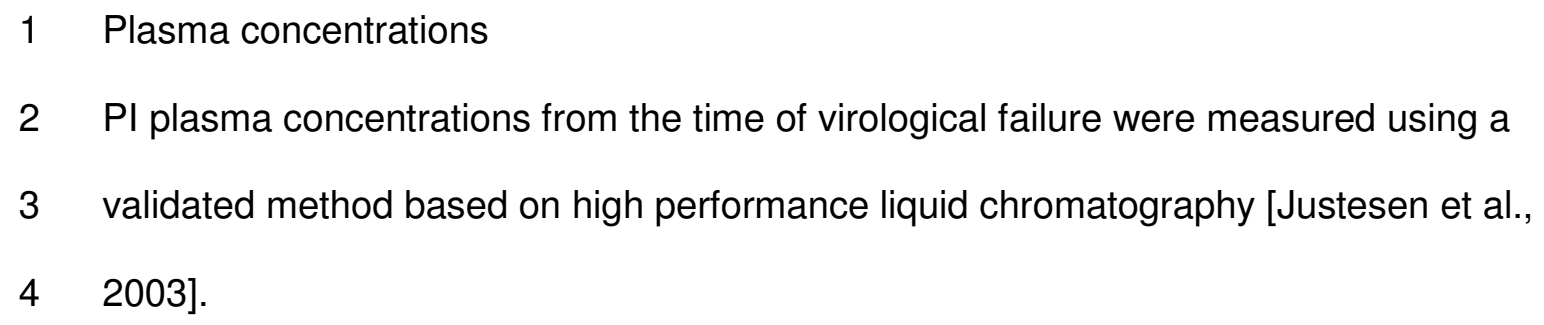




\section{1}

\section{RESULTS}

21007 patients in The Danish HIV Cohort Study database had received ritonavir boosted

3 regimens with Saquinavir, Indinavir, Lopinavir or Atazanavir and had no prior failure to

4 unboosted PI. Among these 1007 patients 36 had experienced virological failure. For

513 of these incompliance was reported in the patient files. The remaining 23 patients

$6(2.3 \%)$ had thus experienced virological failure according to the definition described in

7 the 'Methods' section.

8 Characteristics of the study population as well as the 23 patients experiencing virologi-

9 cal failure are given in Table I. Virological failure experienced by $2.7 \%$ of males (19 out of 707 ) versus $1.3 \%$ of females ( 4 out of 300 ). In total 521 patients started boosted PI after year 2000 of whom 4 (0.8\%) experienced virological failure. This incidence was higher for the years 1995 to 2000 where 3.9\% (19 out of 486) starting $\mathrm{Pl} / \mathrm{r}$ developed virological failure. For patients with a first-line regimen including $\mathrm{Pl} / \mathrm{r} 3.4 \%$ (18 out of 528) developed virological failure compared to $1.0 \%$ (5 out of 479 ) of the patients starting a non- $\mathrm{Pl} / \mathrm{r}$ regimen. The failure rates were similar in the groups of patients starting any treatment before and after 1995 (2.3\% vs. 2.2\%). The incidence rates of failure for each specific $\mathrm{PI} / \mathrm{r}$ regimen were: boosted Saquinavir: 10.8/1000 person years of follow up (PYR) (95\% confidence interval 6.4-18.2) (total 1297 PYR), boosted Indinavir 15.8/1000PYR (95\% confidence interval 7.1-35.2) (total 380 PYR), boosted Lopinavir 1.4/1000PYR (95\% confidence interval 0.2-9.7) (total 731 PYR), and boosted Atazanavir 4.5/1000PYR (95\% confidence interval 1.1-17.8) (total 449 PYR). Nineteen patients attending either of the two clinics in Copenhagen experienced virological failure on $\mathrm{Pl} / \mathrm{r}$ based treatment. These were included for sequence analyses of 24 the pol and gag regions at baseline and at time of virological failure (Table II). For two patients (patients 16 and 17), it was not possible to obtain gag sequences from the failure sample due to the restricted amount of stored material. 
1 The median time between the baseline and failure samples was 44 months (range 24-

2124 months). Fifteen patients were infected with subtype B virus, the remaining four

3 with subtypes A, CRF-01, C and G, respectively (Table II).

4 No patients had major PI resistance mutations at baseline. Patients 6, 10 and 17 de-

5 veloped major $\mathrm{PI}$ resistance mutations during $\mathrm{Pl} / \mathrm{r}$ treatment, in all three cases including

6 L90M. Two had received boosted Saquinavir, and one had received boosted Lopinavir.

7 Patients 7 and 13 developed only minor PI mutations. For the remaining four patients

8 with minor $\mathrm{PI}$ mutations at failure $(2,12,15$ and 16), these were already present at

9 baseline. From ten patients no major or minor PI resistance mutations could be de-

10 tected at time of virological failure.

11 Fifteen patients had mutations related to RT inhibitors (data not shown). In ten patients

12 the mutations developed during the study period and in the remaining five the muta-

13 tions were already present at baseline.

14 Gag sequences were analysed from 19 baseline samples and 17 failure samples. All

15 sequences deviated from the HXB2 reference sequence in one or more positions at the

16 five cleavage sites. Subtype non-B specimens exhibited more nucleotide differences

17 from the subtype $B$ reference than the subtype $B$ sequences. These deviations were

18 typically maintained from baseline to failure and are likely to be subtype specific poly-

19 morphisms.

20 Nine patients developed aa mutations in one or more CS between baseline and failure.

21 Most mutations and polymorphisms were observed at the p2/p7 cleavage site. The

22 most conserved site was p17/p2 with no development of mutations and only one poly-

23 morph position (position 362). Only patients with major or minor mutations in PR devel-

24 oped mutations at the $\mathrm{p} 7 / \mathrm{p} 1$ and $\mathrm{p} 1 / \mathrm{p} 6 \mathrm{CS}$ during failure.

25 Several insertions and deletions relative to the HXB2 reference were observed

26 throughout the gene especially in the $\mathrm{p} 1$ and $\mathrm{p} 6$ regions (data not shown). All except 
1 one were identical at baseline and failure. This was a four aa insertion in p24 in the

2 failure sample of patient 12 (data not shown).

3 Drug concentrations were below target trough value in ten out of the 19 patients ( $\mathrm{Pa}$ -

4 tients $1,4,6,9,11,12,13,15,18$ and 19, see Table II). Saquinavir or Indinavir were

5 not detectable in six out of the 14 patients in whom it was measured. In two of these

6 patients ritonavir was detectable. The remaining eight patients had Saquinavir/Indinavir

7 drug concentrations in a range above the therapeutic limit. For two patients ritonavir

8 was the only drug measured, and in both cases it was undetectable, suggesting the

9 additional PI to be present at low concentrations as well. Lopinavir was detected in one

10 patient receiving this $\mathrm{PI}$, but Atazanavir was below the therapeutic limit in the two pa-

11 tients receiving it. For nine patients, drug concentrations were above target trough

12 value. In these patients the median viral load (VL) was 1,480 copies/ml $(442-30,500)$ at

13 the time of virological failure. For the three patients with major resistance mutations,

14 one had plasma concentrations below target trough value and two had values above. 
1

2 In the present study, $23(2.3 \%)$ of Danish HIV-1 patients on $\mathrm{PI} / \mathrm{r}$ treatment in the period

3 from 1995 to 2008 developed virological failure.

4 The patients included in this study received Indinavir, Saquinavir, Lopinavir or Ata-

5 zanavir as part of the $\mathrm{Pl} / \mathrm{r}$ regimen. Virological failure during Lopinavir/ritonavir treat-

6 ment without the development of PI mutations is well described [Hicks et al., 2004]. In

7 this study comparing previous PR regimens the failure incidence rates were higher in

8 those treated with Saquinavir and Indinavir than in those treated with Lopinavir and

9 Atazanavir (10.8/1000PYR and 15.8/1000PYR vs. 1.4/1000PYR and 4.5/1000PYR respectively). These rates were not corrected for calendar year, backbone treatment and reasons of choice of treatment regimen.

Out of the 19 patients chosen for molecular analyses only three (16\%) developed major PI resistance mutations in PR explaining the viral drug escape. Three patients developed minor mutations in the PR gene, but no major mutations were detected, that could account for the virological failure observed. For the remaining patients sequencing of PR revealed no development of resistance mutations, and the virological failure must, thus, be explained by other factors. These findings are in concordance with findings from other studies, were $0-30 \%$ of virological failures to $\mathrm{Pl} / \mathrm{r}$ were explained by $\mathrm{PR}$ mutations [Ananworanich et al., 2006; von Wyl et al., 2007].

Previous studies have shown low $\mathrm{PI}$ concentrations in patients failing $\mathrm{Pl} / \mathrm{r}$ regimens and high intra- and inter-patient variability [Zazzi, 2007; Masquelier et al., 2005; Best et al., 2007]. In accordance with these observations the present study found that drug concentrations were below target trough value in ten out of the 19 patients. Only one patient with measured plasma concentrations below target trough value developed major mutations. In the remaining nine patients with low PI concentrations the detected VL was caused by replicating wild type virus. Patients who are incompliant, but take their medication prior to sampling, will appear with measureable plasma drug concentra- 
1 tions, but high VL and wild type virus due to the delayed viral response. This could ex-

2 plain the observed pattern in these patients.

3 Samples were unlikely to have been collected immediately before a dose, so it is pos-

4 sible that some of these patients may in fact have had too low trough levels. Drug con-

5 centrations were only measured for one time point for each patient. Sequential meas-

6 urements might have given a more complete picture of the actual situation. The drug

7 concentrations below target trough level are likely to be explained by poor compliance

8 even though this was considered when selecting the study population. Information on

9 compliance was not collected prospectively but evaluated looking through patient files

10 and no data for successful compliance were collected. Even for patients with no com-

11 pliance issues registered these might have been contributing to the virological failure observed. Drug levels equal to zero makes altered absorption or metabolism unlikely

13 explanations.

14 Baseline and failure gag sequences were analysed for seventeen patients. Gag muta15 tion development from baseline to failure at the p7/p1 and p1/p6 CS was only seen to16 gether with the development of major or minor PR mutations. In none of the 19 failure 17 cases analysed in this study it could be confirmed that these gag mutations had given rise to resistance development and virological failure on their own. Mutations in

19 p24/p17 and p2/p7 were observed independently of PR mutations at positions 128,

$20132,376,381$. These positions have not been linked previously to PR resistance de-

21 velopment.

22 Variations from the reference sequence in $\mathrm{p} 7 / \mathrm{p} 1$ and $\mathrm{p} 1 / \mathrm{p} 6$ were observed at positions $428,431,437,449,451$ and 452 including the $431 \mathrm{~V}, 437 \mathrm{~V}$ and $452 \mathrm{~S}$ variants de-

24 scribed in previous studies in relation to PI resistance development [Zhang et al., 1997;

25 Verheyen et al., 2006; Nijhuis et al., 2007; Myint et al., 2004; Malet et al., 2007]. These

26 variants were present at baseline as well as at the time of virological failure. They were

27 therefore most likely present during the period of viral suppression observed in all pa- 
1 tients according to the criteria and did thus not prevent viral suppression. Previous

2 studies have shown that certain CS mutations might contribute directly to PI resistance

3 by improving cleavage efficiency by wild type PR [Verheyen et al., 2006; Nijhuis et al.,

4 2007; Prabu-Jeyabalan et al., 2004]. In the present study it could not be confirmed that

5 this was of any significance for the limited amounts of virological failure cases ob-

6 served.

7 In conclusion, virological failure is infrequent in patients on a $\mathrm{Pl} / \mathrm{r}$ based regimen. The

8 proportion of patients failing $\mathrm{Pl} / \mathrm{r}$ treatment has decreased during the years 1995-2008.

9 PR resistance mutations and low drug levels could account for $12(63 \%)$ of the failure

10 cases observed. The analyses of gag sequences did not confirm a significant role of

11 gag CS mutations in resistance development among the limited amount of failure pa-

12 tients with virological failure to $\mathrm{Pl} / \mathrm{r}$. The use of regimens evaluated in the present study

13 has decreased over the years, and are only used for a minority of present day patients

14 in Denmark. 


\section{ACKNOWLEDGEMENTS}

2 The authors would like to thank "the Danish Medical Research Council" and "Fhv. Di-

3 rektør Leo Nielsen og Hustru Karen Margrethe Nielsens Legat for Lægevidenskabelig

4 Grundforskning" for research grants. The study was furthermore supported by an unre-

5 stricted grant from ABBOTT Laboratories (Copenhagen, Denmark). 
1

2

3

4

5

6

7

8

9

10

11

12

13

14

15

16

17

18

19

20

21

22

23

24

25

26

27

\section{REFERENCES}

Ananworanich J, Hirschel B, Sirivichayakul S, Ubolyam S, Jupimai T, Prasithsirikul

W, Chetchotisakd P, Kiertiburanakul S, Munsakul W, Raksakulkarn P, Tan-

suphasawadikul S, Schutz M, Snowden W, Ruxrungtham K; Staccato Study Team.

2006. Absence of resistance mutations in antiretroviral-naïve patients treated with ritonavir-boosted Saquinavir. Antivir Ther 11:631-635.

Aoki M, Venzon DJ, Koh Y, Aoki-Ogata H, Miyakawa T, Yoshimura K, Maeda K, Mitsuya H. 2009. Non-cleavage site gag mutations in amprenavir-resistant human immunodeficiency virus type 1 (HIV-1) predispose HIV-1 to rapid acquisition of amprenavir resistance but delay development of resistance to other protease inhibitors. J Virol. 83(7):3059-68.

Ashorn P, McQuade TJ, Thaisrivongs S, Tomasselli AG, Tarpley WG, Moss B. 1990. An inhibitor of the protease blocks the maturation of human and simian immunodeficiency viruses and the spread of infection. PNAS 87:7472-7476.

\section{Bally F, Martinez R, Peters S, Sudre P, Telenti A. 2000. Polymorphism of HIV type} 1 gag p7/p1 and p1/p6 cleavage sites: clinical significance and implications for resistance to protease inhibitors. AIDS Res Hum Retroviruses 16(13):1209-13

Best BM, Goicoechea M, Witt MD, Miller L, Daar ES, Diamond C, Tilles JG, Kemper CA, Larsen R, Holland DT, Sun S, Jain S, Wagner G, Capparelli EV, McCutchan JA, Haubrich RH; California Collaborative Treatment Group 578 Study Team. 2007. A randomized controlled trial of therapeutic drug monitoring in treatment-naïve and experienced HIV-1-infected patients. J Acquir Immune Defic Syndr $46: 433-442$. 
Borman AM, Paulos S, Clavel F. 1996. Resistance of human immunodeficiency virus type 1 to protease inhibitors. Selection of resistance mutations in the presence and absence of the drug. J Gen Virol 77:419-426.

Cooper CL, van Heewijk RP, Gallicano K, Cameron DW. 2003. A review of lowdose ritonavir in protease inhibitor combination therapy. Clin Infect Dis 36:15851592.

Croteau G, Doyon L, Thibeault D, McKercher G, Pilote L, Lamarre D. 1997. Impaired fitness of human immunodeficiency virus type 1 variants with high-level resistance to protease inhibitors. J Virol 71:1089-1096.

Doyon L, Croteau G, Thibeault D, Poulin F, Pilote L, Lamarre D. 1996. Second locus involved in human immunodeficiency virus type 1 resistance to protease inhibitors. J Virol 70:3763-3769.

23

24 Ghosn J, Delaugerre C, Flandre P, Galimand J, Cohen-Codar I, Raffi F, Norton M, 25 Delfraissy JF, Rouzioux C, Chaix ML. 2009. Baseline number of substitutions in 26 Gatanaga H, Suzuki Y, Tsang H, Yoshimura K, Kavlick MF, Nagashima K, Gorelick RJ, Mardy S, Tang C, Summers MF, Mitsuya H. 2002. Amino acid substitutions in Gag protein at non-cleavage sites are indispensable for the development of high multitude of HIV-1 resistance against protease inhibitors. J Biol Chem 277:59525961. p2/NC site of Gag gene is predivtive of virological failure in patients randomized to 
1

2

3

4

5

6

7

8

9

10

11

12

13

14

15

16

17

18

19

20

21

22

23

24

25

26

9

24

first-line Lopinavir/ritonavir single drug regimen: week 96 results of the Monark trial. $16^{\text {th }}$ conference on retroviruses and opportunistic infections (CROI)

Gulnik SV, Suvorov LI, Liu B, Yu B, Anderson B, Mitsuya H, Erickson JW. 1995. Kinetic characterization and cross-resistance patterns of HIV-1 protease mutants selected under drug pressure. Biochem 34:9282-9287.

Hicks C, King MS, Gulick RM, White AC Jr, Eron JJ Jr, Kessler HA, Benson C, King KR, Murphy RL, Brun SC. 2004. Long-term safety and durable antiretroviral activity of Lopinavir/ritonavir in treatment-naïve patients: 4 year follow-up study. AIDS 18:755-779.

2

3 http://www.hiv.lanl.gov/

4

5 Justesen US, Pedersen C, Klitgaard NA. 2003. Simultaneous quantitative determi-

6 nation of the HIV protease inhibitors Indinavir, amprenavir, ritonavir, Lopinavir, Sa-

7 quinavir, nelfinavir and the nelfinavir active metabolite M8 in plasma by liquid chro-

8 matography. J Chromatogr B Analyt Technol Biomed Life Sci 783:491-500.

Jorgensen LB, Christensen MB, Gerstoft J, Mathiesen LR, Obel N, Pedersen C,

1 Nielsen $\mathrm{H}$, Nielsen C. Prevalence of drug resistance mutations and non-B subtypes

22 in newly diagnosed HIV-1 patients in Denmark. Scand J Infect Dis. 2003;35(11-

3 12):800-7

5 Katz R, Skalka A. 1994. The retroviral enzymes. Annu Rev Biochem 63:133-173. 
1 Leitner T, Escanilla D, Marquina S, Wahlberg J, Broström C, Hansson HB, Uhlén

2 M, Albert J. 1995. Biological and molecular characterization of subtype D, G and 3 A/D recombinant HIV-1 transmissions in Sweden. Virol 209:136-146.

$5 \quad$ Lima VD, Gill VS, Yip B, Hogg RS, Montaner JS, Harrigan PR. 2008. Increased

6 Resilience to the Development of Drug Resistance with Modern Boosted Protease

7 Inhibitor- Based Highly Active Antiretroviral Therapy. The Journal of Infectious Dis-

$8 \quad$ eases 198:51-8.

9

Liu TF, Shafer RW, 2006. Web Resources for HIV type 1 Genotypic-Resistance

11 Test Interpretation. Clin Infect Dis 42(11):1608-18. Epub 2006 Apr 28

Loeb DD, Hutchinson III CA, Adgell MH, Farmerie WG, Swanstrom R. 1989. Mutational analysis of human immunodeficiency virus type 1 protease suggests func-

Lohse N, Hansen AB, Jensen-Fangel S, Kronborg G, Kvinesdal B, Pedersen C, Larsen CS, Møller A, Willumsen L, Obel N. 2005. Demographics of HIV-1 infection in Denmark: Results from The Danish HIV Cohort Study. Scand J Infect Dis, 37:338-343.

21

Madsen TV, Leitner T, Lohse N, Obel N, Ladefoged K, Gerstoft J, Petersen AB, 
Malet I, Roquebert B, Dalban C, Wirden M, Amellal B, Agher R, Simon A, Katlama C, Costagliola D, Calvez V, Marcelin AG. 2007. Association of Gag cleavage sites to protease mutations and to virological response in HIV-1 treated patients. J Infect 54:367-374.

Mammano F, Petit C, Clavel F. 1998. Resistance-associated loss of viral fitness in human immunodeficiency virus type 1: Phenotypic analysis of protease and gag coevolution in protease inhibitor-treated patients. J Virol 72:7632-7637.

Mammano F, Trouplin V, Zennou V, Clavel F. 2000. Retracing the evolutionary pathways of human immunodeficiency virus type 1 resistance to protease inhibitors: virus fitness in the absence and in the presence of drug. $\mathrm{J}$ Virol 74:8524-8531.

Masquelier B, Pereira E, Peytavin G, Descamps D, Reynes J, Verdon R, Fleury H, Garraffo R, Chêne G, Raffi F, Brun-Vézinet F; APROCO/COPILOTE Study Group. 2005. Intermittent viremia during first-line, protease inhibitors-containing therapy: significance and relationship with drug resistance. J Clin Virol 33:75-78.

McQuade TJ, Tomasselli AG, Liu L, Karacostas V, Moss B, Sawyer TK, Heinrikson RL, Tarpley WG. 1990. A synthetic HIV-1 protease inhibitor with antiviral activity arrests HIV-like particle maturation. Science 247:454-456.

Moyle GJ, Back D. 2001. Principles and practice of HV-protease inhibitor pharmacoenhancement. HIV Medicine 2:105-113.

Myint L, Matsuda M, Matsuda Z, Yokomaku Y, Chiba T, Okano A, Yamada K, Sugiura W. 2004. Gag non-cleavage site mutations contribute to full recovery of viral 
1 fitness in protease inhibitor-resistance human immunodeficiency virus type 1. An2 timicrob Agents Chermother 48:444-452.

Nijhuis M, Schuurman R, de Jong D, Erickson J, Gustchina E, Albert J, Schipper P,

5 Gulnik S, Boucher CA. 1999. Increased fitness of drug resistant HIV-1 protease as

6 a result of acquisition of compensatory mutations during suboptimal therapy. AIDS

$7 \quad$ 13:2349-2359.

8

9 Nijhuis M, van Maarseveen NM, Lastere S, Schipper P, Coakley E, Glass B, Rovenska M, de Jong D, Chappey C, Goedegebuure IW, Heilek-Snyder G, Dulude D, Cammack N, Brakier-Gingras L, Konvalinka J, Parkin N, Kräusslich HG, BrunVezinet F, Boucher CA. 2007. A novel substrate-based HIV-1 protease inhibitor drug resistance mechanism. PLoS Med 4:e36. site with a V82A drug-resistant mutation in viral protease. J Virol 78:12446-12454. Hirschel B, Vernazza PL, Bernasconi E, Rickenbach M, Perrin L, Ledergerber B,

Verheyen J, Litau E, Sing T, Däumer M, Balduin M, Oette M, Fätkenheuer G, Rockstroh JK, Schuldenzucker U, Hoffmann D, Pfister H, Kaiser R. 2006. Compensatory mutations at the HIV cleavage sites p7/p1 and p1/p6 in therapy-naïve and therapy-experienced patients. Antivir Ther 11:879-887. Günthard HF; for the Swiss HIV Cohort Study. 2007. Emergence of HIV-1 Drug Resistance in Previously Untreated Patients Initiating Combination Antiretroviral 
1 Treatment A Comparison of Different Regimen Types. ARCH INTERN MED

$2 \quad 167(16): 1782-90$.

3

4 Zazzi M, 2007. Lack of major resistance mutations in HIV-1 protease at failure of

5 boosted protease inhibitor-based firstline antiretroviral treatment. Reviews in antivi-

$6 \quad$ ral therapy 2: 4-12

7

8 Zhang YM, Imamichi H, Imamichi T, Lane HC, Falloon J, Vasudevachari MB, Salz-

9 man NP. 1997. Drug resistance during Indinavir therapy is caused by mutations in

10 the protease gene and in its gag substrate cleavage sites. J Virol 71:6662-6670. 